\title{
Study of malignant tumours of the uterine corpus: histopathology and immunohistochemistry
}

\author{
Zahida O. A. ${ }^{1 *}$, Mohammad Niaz ${ }^{2}$, Krishnaraj Upadhyaya ${ }^{3}$
}

\begin{abstract}
${ }^{1}$ Department of Pathology, Kanachur Institute of Medical Science and Research Centre, Manglaore, Karnataka, India ${ }^{2}$ Department of Orthopaedics, Aster Al Raffa Hospital, Muscat, Oman

${ }^{3}$ Department of Pathology, Yenepoya Medical Collage, Manglaore, Karnataka, India
\end{abstract}

Received: 24 June 2020

Accepted: 30 July 2020

\author{
*Correspondence: \\ Dr. Zahida O. A., \\ E-mail: zahida.oa@gmail.com
}

Copyright: () the author(s), publisher and licensee Medip Academy. This is an open-access article distributed under the terms of the Creative Commons Attribution Non-Commercial License, which permits unrestricted non-commercial use, distribution, and reproduction in any medium, provided the original work is properly cited.

\begin{abstract}
Background: The uterine corpus represents the second most common site for malignancy in the female genital tract. This study was performed to ascertain the profile of malignant tumours of the uterine corpus reported at our centre.

Methods: A retrospective analysis of cases retrieved from the archives of the department of pathology from January 2014 to December 2016. Clinical information of the patients was collected from the hospital records. Classification and grading of the tumours were done according to the current WHO classification.

Results: Nineteen cases were studied. There were ten cases of endometrial adenocarcinoma, five cases of leiomyosarcoma, three cases of endometrial stromal sarcoma and one case of carcinosarcoma(malignant mixed mullerian tumour). The age range of endometrial adenocarcinoma was 55 to 85 years and presented with post menopausal bleeding, whereas endometrial stromal sarcomas occurred in women above 45 years of age. Leiomyosarcomas had age range from 26 to 65 years. All leiomyosarcomas were clinically diagnosed as fibroid. Majority of endometrial adenocarcinomas were well differentiated endometroid type. Out of the three endometrial stromal sarcomas two were high grade, one with metastasis. All leiomyosarcomas showed mitotic rate above 10/10hpf.

Conclusions: Endometrial carcinomas form the majority of malignant tumours of uterine corpus and occur in older age group followed by leiomyosarcomas. Endometrial stromal sarcomas are less common and occur in middle aged and older patients. Leiomyosarcomas and stromal sarcomas are usually misdiagnosed as fibroids clinically unless metastases are present.
\end{abstract}

Keywords: Uterine corpus, Endometrial carcinomas, Carcinosarcoma

\section{INTRODUCTION}

Cancer presents an ever growing threat to humanity. The incidence and prevalence of different types of cancer differ around the world owing to the multifactorial nature of carcinogenesis. Uterine cancer is the $4^{\text {th }}$ most malignancy in women following breast, lung and colorectal malignancy. The uterine corpus represents the second most common site for malignancy of the female genital system. However, these tumours are relatively rare and exhibit a significant difference in incidence rates between developed and developing nations, 4.7 per 100,000 in developed nations and 5.5 per 100,000 in developing nations. ${ }^{1}$ However, this vast disparity in incidence rates is closing fast in countries such as India with the age standardized incidence rates predicted to rise by a significant amount within the next twenty years. ${ }^{2}$ Tumours of the uterine corpus are divided into epithelial, mesenchymal, mixed epithelial-mesenchymal, miscellaneous, lymphoid and secondary tumours. ${ }^{3}$ 


\section{METHODS}

A retrospective study was done with cases collected over a period of three years from January 2014 to December 2016. The relevant clinical details were collected from archives of the Department of Pathology. All demographic data such as age, gender and clinical history were recorded from the Archives. The specimens were all fixed in $10 \%$ formalin for $24-48$ hours. Detailed gross examination was done and tissue bits from representative areas were taken. The tissue bits were processed in an automated tissue processor overnight. Paraffin blocks were prepared and five micron thick sections were cut and stained with routine haematoxylin and eosin. The slides were reviewed with ancillary immunehistochemical studies(alpha-actin, smooth muscle, cloneep188, source-rabbit monoclonal) and the tumours were morphologically classified according to the current WHO classification. $^{3}$

\section{RESULTS}

There were total of nineteen cases of primary malignant tumours of the uterine corpus out of which ten were endometrial carcinomas(52.63\%), five were leiomyosarcomas $(26.32 \%)$, three were endometrial stromal sarcomas(15.79\%), and one was a carcinosarcoma(malignant mixed mullerian tumour) (Figure 1, Figure 2). The details of the cases are shown in (Table 1). The tumours were seen to occur in a wide age range, the youngest case being 19 years old and the oldest 85 years. Overall, the 50-59 age group showed the most number of cases( 6 cases) followed by the 40-49 age group ( 5 cases) and the 60-69 age group( 3 cases). The endometrial carcinomas showed a clear spike in the 50-59 age group and all the endometrial stromal sarcomas occurred in women above 45 years of age. Leiomyosarcomas had age range from 26 to 65 years. On analysis, it was found that the mean age for epithelial tumours was 52.8 years and for mesenchymal tumours it was 48.75 years.

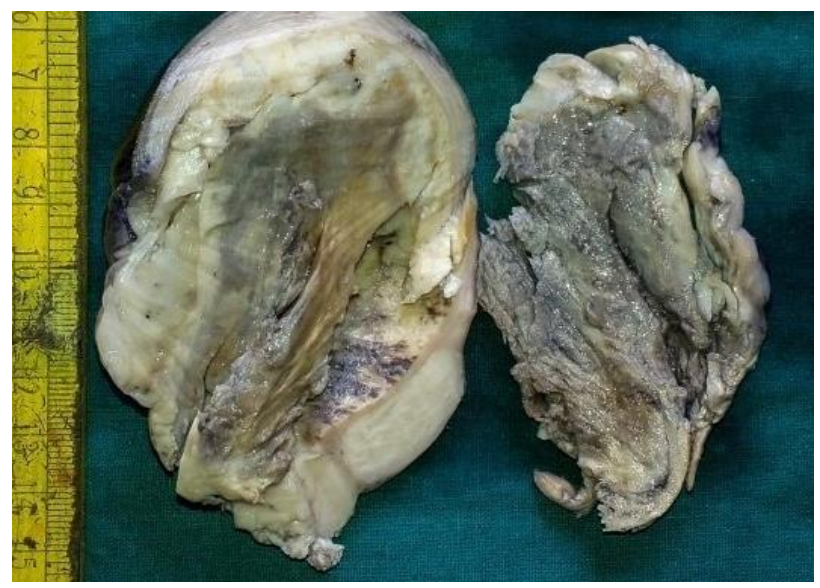

Figure 1: Cut surface of mixed malignant Mullerian tumours showing pale white and greyish polypoidal growth in the endometrial cavity.

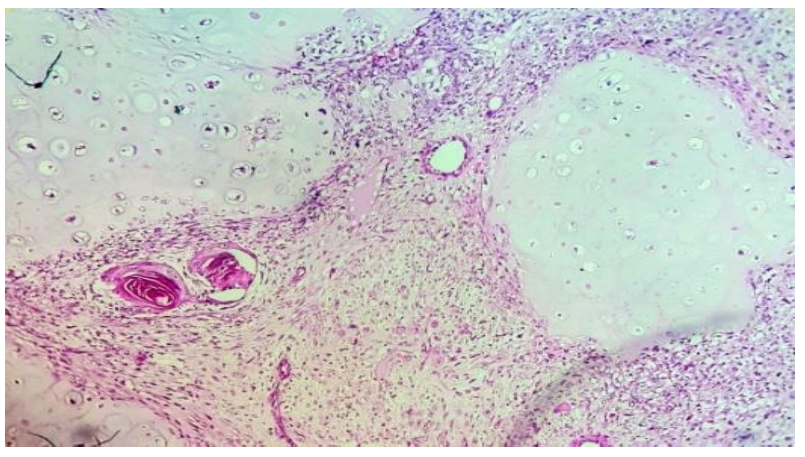

Figure 2: Photomicrograph of mixed malignant Mullerian tumour showing cartilaginous differentiation (right), keratin pearls (left) within the tumour. (H\&E 10X).

Table 1: Details of the various tumours in our study.

\begin{tabular}{|lllll|}
\hline Histological type & & Age group & Number of cases & $\begin{array}{c}\text { Percen } \\
\text { tage }\end{array}$ \\
\hline Epithelial tumours & Endometrioid carcinoma & $40-59 y r s$ & 10 & 52.63 \\
\hline Mesenchymal tumours & Leiomyosarcoma & $26-65 y r s$ & 5 & 42.11 \\
\hline & $\begin{array}{l}\text { Endometrial stromal } \\
\text { sarcoma }\end{array}$ & $45-65 y r s$ & 3 & 5.26 \\
\hline $\begin{array}{l}\text { Mixed epithelial and } \\
\text { mesenchymal tumours }\end{array}$ & $\begin{array}{l}\text { Malignant mixed mullerian } \\
\text { tumour }\end{array}$ & 85 yrs & 1 & 5 \\
\hline
\end{tabular}

Clinically all the ten cases of endometrial carcinoma presented with irregular menstrual cycle and menorrhagia. Among these, six cases $(31.5 \%)$ presented with post menopausal bleeding, whereas in the cases diagnosed as leiomyosarcoma and endometrial stromal sarcoma malignancy was not suspected clinically. The case diagnosed as malignant mixed mullerian tumour was suspected on the endometrial curettings.

One of the cases of endometrial carcinoma was a 19 year old female who presented with dysmenorrhea. On ultrasonaography, a polyp was seen protruding from cervix to vagina and also sigmoid bowel thickening with 
sigmoid polyposis. Biopsies from the colon was reported as tubular adenoma and from the cervix showed adenosquamous carcinoma(Figure 3). This was followed by hemiocolectomy and hysterectomy. There was a family history of colonic polyps and carcinoma(familial polyposis syndrome).

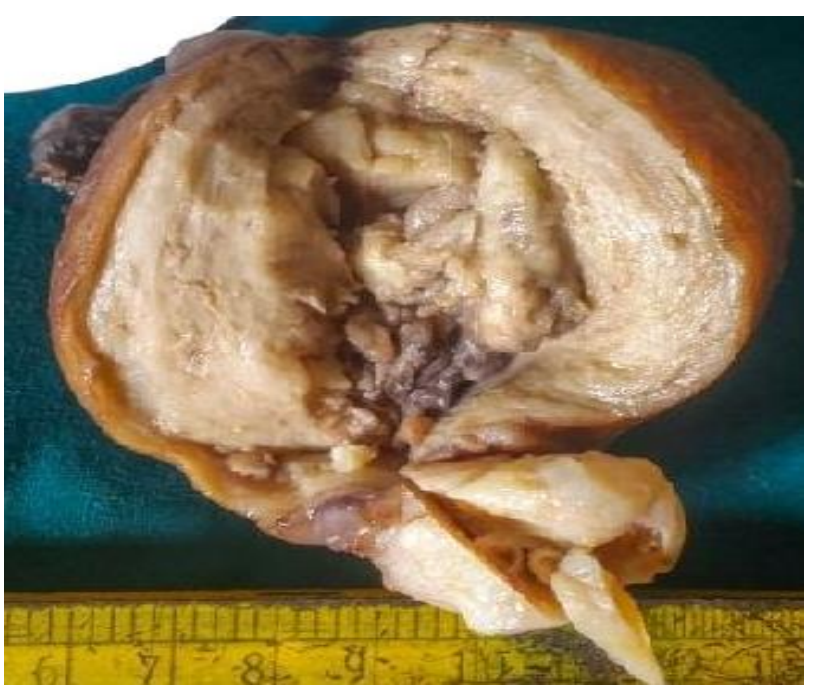

Figure 3: Cut surface of adenosquamous carcinoma of uterus with polpoidal growth filling the endometrial cavity and protruding into the cervical canal.

Endometrioid carcinomas include endometrioid carcinoma of the usual type or variant with squamous differentiation and villoglandular and secretory variants. Other types are mucinous, serous, clear cell and neuroendocrine, as well as mixed, undifferentiated and dedifferentiated carcinomas. Out of the ten endometrial adenocarcinomas in our study, five were endometrioid type, three were villoglandular variant, one was serous papillary adenocarcinoma and one was with squamous differentiation.

Among the $42.11 \%$ mesenchymal tumours, three were endometrial stromal sarcomas $(15.79 \%)$ and five were leiomyosarcomas(26.32\%)(Figure 4). The criteria which were applied to diagnose leiomyosarcoma were infiltrating margin, mitotic activity(10 or more per 10HPF), presence of necrosis and absence of hyalinization. The endometrial stromal sarcoma should be considered as a differential diagnosis where immunohistochemistry(IHC) for smooth muscle actin (SMA) is helpful. IHC for smooth muscle actin was done for all the sarcomas, which showed negative staining for endometrial stromal sarcomas and positive staining for leiomyosarcomas(Figure 5).

\section{DISCUSSION}

Gynaecological cancers continue to be important health problems worldwide. In India female genital cancer incidence ranges from $22.4 \%$ to $55.8 \% .^{4}$ Endometrial carcinoma is the most common type of malignancy of the corpus(95\%). Sarcoma represents only $4 \%$ and other heterologous tumours such as rhabdomyosarcoma, osteosarcoma and chondrosarcoma represent remaining $1 \%$ of malignant tumours. In about $10 \%$ of the endometrioid carcinomas variants like ciliated variant, mucinous variant, serous variant, villoglandular variant and variant with squamous differentiation are seen. Carcinosarcomas are mixed epithelial and mesenchymal tumours having worst prognosis. Endometrial stromal tumours can be benign and malignant(low grade and high grade). ${ }^{5}$
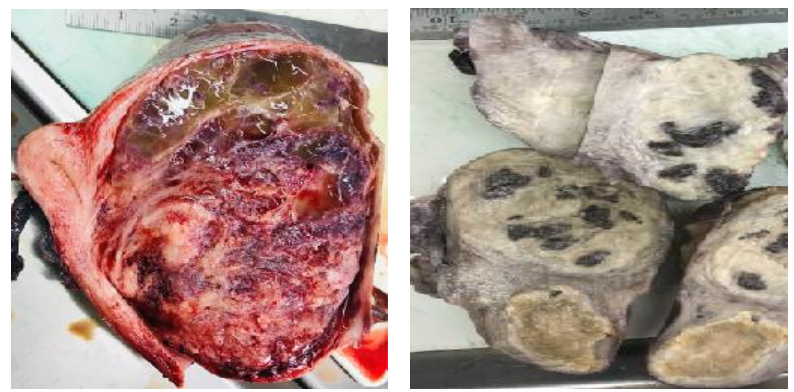

Figure 4: cut surface of endometrial stromal A) sarcoma and B) leiomyosarcoma.

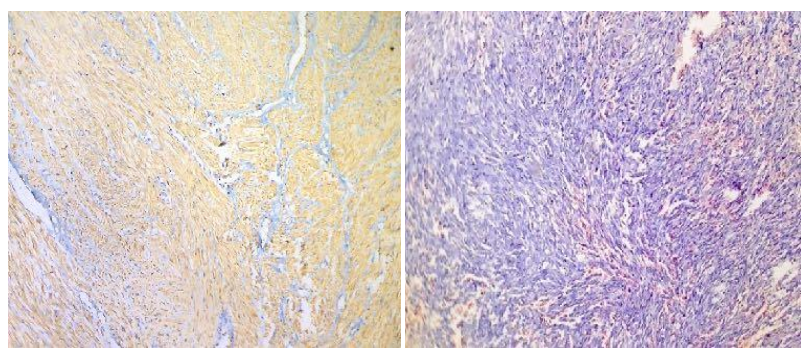

Figure 5: photomicrography from leimyosarcoma A) showing positive staining and endometrial stromal sarcoma, B) showing negative staining (IHC SMA, 10X).

In our study we found that endometrial epithelial tumours were the majority of cases $(52.63 \%)$, followed by mesenchymal tumours. The most number of cases were in the age group of 50-59years.

Benediktsdottir et al found 12 types of malignant tumours of uterine corpus among which epithelial tumours comprised majority of the cases(91.4\%), mesenchymal tumours $5 \%$ and mixed malignant tumours $3 \% .^{6}$ Study done by Tan et al of the uterine cancer pattern in Singapore, observed that out of 165 cases, endometrioid adenocarcinoma was the commonest type of uterine cancer(75.2\%), followed by uterine $\operatorname{sarcoma}(11.5 \%){ }^{7}$ Similar studies done by other authors Chang et al. and Defusco et al. ${ }^{8,9}$ also found similar results.

Aryra et al study showed a total of 17 malignant cases of the uterine corpus, out of which $14(82.3 \%)$ cases were 
endometrial carcinoma and our study showed $52.63 \%$ of endometrial carcinoma which is slightly higher. In their study showed maximum number of cases of malignant tumours was seen in the age range of 51-60 years, ${ }^{10}$ which is similar to our study.

Table 2: The comparison between the various studies.

\begin{tabular}{|c|c|c|c|c|}
\hline Study & No. of cases & $\begin{array}{l}\text { Epithelial } \\
\text { tumours }\end{array}$ & Mesenchymal tumours & $\begin{array}{l}\text { Mixed epithelial and } \\
\text { mesenchymal tumours }\end{array}$ \\
\hline Benediktsdottir et al $^{6}$ & 338 & $91.4 \%$ & $5 \%$ & $3.0 \%$ \\
\hline Arya et al ${ }^{10}$ & 17 & $82.4 \%$ & $11.8 \%$ & - \\
\hline Hemalata et al $^{11}$ & 27 & $88.9 \%$ & $11.1 \%$ & - \\
\hline N'Dah et $^{\prime} \mathbf{l}^{12}$ & 165 & $67.6 \%$ & $32.7 \%$ & - \\
\hline Present study & 19 & $52.63 \%$ & $42.11 \%$ & $5.26 \%$ \\
\hline
\end{tabular}

Hemalata et al, in a 10 year study found that epithelial tumours were predominant in number $(88.9 \%)$ followed by mesenchymal tumours $(11.1 \%)$, and most of the cases were in between the age group of 51-60 years. ${ }^{11}$ These findings coincide with our study.

N'Dah et al. studied epidemiological and histo-logical aspects of Women Genital Cancers in Côte d'Ivoire and found uterine carcinoma with predominant cases $67.6 \%$ and uterine sarcomas 32.7\%. ${ }^{12}$ Our study has similar findings. Table 2 shows details of the various studies.

\section{CONCLUSION}

Our study concluded that endometrial carcinomas form the majority of malignant tumours of uterine corpus and occurs in the older age group which is in concordance with other studies in the literature. This is followed by leiomyosarcomas with a wide age range. Endometrial stromal sarcomas are less common. Malignant mixed mullerian tumours are very rare and seen in the post menopausal age.

\section{Funding: No funding sources}

Conflict of interest: None declared

Ethical approval: The study was approved by the Institutional Ethics Committee

\section{REFERENCES}

1. Torre L, Bray F, Siegel R, Ferlay J, Lortet-Tieulent J, Jemal A. Global cancer statistics, 2012. Cancer Journal for Clinicians. 2015;65(2):87-108.

2. Globocan Available at: http://globocan.iarc.fr. Accessed on 25 May 2020.

3. Kurman RJ, Carcangiu ML, Herrington CS, Young RH. WHO Classification of tumours of female reproductive organs. 4th ed. France: IARC Press; 2014.
4. Nkyekyer K. Pattern of gynecological cancers in Ghana. East Afr Med J.2000;77:534-8.

5. Rosai J. Rosai and Ackerman's Surgical Pathology. 10th ed. London: Elsevier Health Sciences; 2011: 1490-1521.

6. Benediktsdóttir K, Jónasson J, Hallgrímsson J. Tumours in Iceland. Malignant tumours of the corpus of the uterus. APMIS. 1989;97(7-12):781-6.

7. Tan YY, Ho TH. Uterine cancer--KK Hospital experience. Singapore Med J. 1996;37(6):600-3.

8. Chang KL, Crabtree GS, Lim-Tan SK, Kempson RL, Hendrickson MR. Primary uterine endometrial stromal neoplasm. A clinicopathological study of 117 cases. Am J Surg Pathol. 1990;14(5):415-38.

9. De Fusco PA, Gaffey TA, Malkasian GD, Long HJ, Cha SS. Endometrial stromal sarcoma: review of Mayo Clinic experience, 1945-1980. Gynecol Oncol. 1989;35(1):8-14.

10. Arya A, Narula R, Narula K, Singh S. Retrospective and prospective study of benign and malignant uterine corpus tumours. National Journal of Integrated Research in Medicine. 2013;4(6):5-10.

11. Hemalatha A, Gayathri M, Ramesh D, Chamarthy N, Giripunja M, Nayana N. Evaluation of trends in the profile of gynaecologic malignancies at a tertiary care hospital in Karnataka, South India. Intenat $\mathrm{J}$ of Med Res \& Health Sci. 2013;2(4):870.

12. N'Dah KJ, Doukoure B, Troh E, Aman NA, Koffi, $\mathrm{KE}$, Kouamé AD, et al. Epidemiological and Histological Aspects of Women Genital Cancers in Côte d'Ivoire. Open Journal of Obstetrics and Gynecology. 2014;4:516-23.

Cite this article as: Zahida OA, Niaz M, Upadhyaya $\mathrm{K}$. Study of malignant tumours of the uterine corpus: histopathology and immunohistochemistry. Int J Reprod Contracept Obstet Gynecol 2020;9:3843-6. 